\title{
The association between maternal nutrition and lifestyle during pregnancy and 2-year-old offspring adiposity: analysis from the ROLO study
}

\author{
Mary K. Horan $^{1}$ - Jean M. Donnelly ${ }^{1}$ - Ciara A. McGowan ${ }^{1} \cdot$ Eileen R. Gibney $^{2}$. \\ Fionnuala M. McAuliffe ${ }^{1}$
}

Received: 15 March 2016 / Accepted: 25 May 2016 / Published online: 9 June 2016

(C) The Author(s) 2016. This article is published with open access at Springerlink.com

\begin{abstract}
Aim To examine the association between maternal nutrition and lifestyle factors and offspring adiposity, using baseline and 2-year postpartum follow-up data from a randomised control trial of low glycaemic index diet.

Subject and methods Food diaries and lifestyle questionnaires were completed during pregnancy and infant feeding and maternal lifestyle questionnaires 2 years postpartum for 281 mother and infant pairs from the ROLO study. Maternal anthropometry was measured throughout pregnancy and infant and maternal anthropometry was measured 2 years postpartum.

Results Maternal 2 year postpartum body mass index (BMI) was positively associated with offspring BMI-for-age z-score $(B=0.105, p=0.015)$. Trimester 2 saturated fat intake was positively associated with offspring subscapular:triceps skinfold ratio $(B=0.018, p=0.001)$. Trimester 1 glycaemic index was also positively associated with offspring sum of subscapular and triceps skinfolds $(B=0.009, p=0.029)$. Conclusions Maternal BMI 2 years postpartum was positively associated with offspring BMI. Pregnancy saturated fat intake was positively and polyunsaturated fat negatively
\end{abstract}

Trial Registration: Current Controlled Trials ISRCTN54392969

Electronic supplementary material The online version of this article (doi:10.1007/s10389-016-0740-9) contains supplementary material, which is available to authorized users.

Fionnuala M. McAuliffe

fionnuala.mcauliffe@ucd.ie

1 UCD Obstetrics and Gynaecology, School of Medicine and Medical Science, University College Dublin, National Maternity Hospital, Dublin 2, Ireland

2 Science Centre - South, University College Dublin School Of Agriculture \& Food Science, Belfield, Dublin 4, Ireland associated with offspring adiposity. While further research is necessary, pregnancy and the postpartum period may be early opportunities to combat childhood obesity.

Keywords Foetal programming $\cdot$ Maternal nutrition · Childhood obesity $\cdot$ Glycaemic index

\section{Introduction}

While the importance of the in utero environment throughout the different stages of pregnancy is well established for normal foetal growth and development ( $\mathrm{Wu}$ et al. 2004), there is increasing interest in its role in foetal programming particularly in the area of maternal overnutrition as rates of maternal overweight and obesity increase worldwide (Alexandra et al. 2011; Black et al. 2013; Fisher et al. 2013; Lau et al. 2011; Reynolds et al. 2010; Rogers 2003). Foetal programming of overweight and obesity appears to occur in large for gestational weight infants as well as small for gestational weight infants resulting in a U- or J-shaped curve of higher childhood and adulthood body mass index (BMI) at both extremes of high and low birthweight (Barker 2004; Curhan et al. 1996a, 1996b; Parsons et al. 2001; Rogers 2003; Sayer et al. 2004). Macrosomia results in greater risk of childhood (Blair et al. 2007; Oken and Gillman 2003; Yu et al. 2007) and adulthood (Serdula et al. 1993; Srinivasan et al. 1996) overweight and obesity as overweight and obesity track from infancy throughout life (Catalano and Ehrenberg 2006; Rogers 2003; Sayer et al. 2004).

To date, some studies have found that specific aspects of maternal diet are associated with offspring adiposity such as protein intake (Cuco et al. 2006; Maslova et al. 2014a, 2014b), saturated (Horan et al. 2014c; Murrin et al. 2013), trans 
(Cohen et al. 2011; Dirix et al. 2009) and polyunsaturated (De Vries et al. 2014; Donahue et al. 2011; Hauner et al. 2012; Moon et al. 2012) fatty acid intake and dietary glycaemic index (GI; Horan et al. 2014c; Moses et al. 2006; Okubo et al. 2014; Walsh et al. 2012b). However, study results are often conflicting (Brion et al. 2010; Moses et al. 2014; Walsh et al. 2012b).

In addition, there has been little research into the effect of low GI healthy eating interventions in pregnancy on maternal weight postpartum in euglycaemic women. Interventions in gestational diabetes mellitus (GDM) have shown little success after pregnancy (Fehler et al. 2007; Louie et al. 2015; Stage et al. 2004). Mothers from the ROLO (Randomised cOntrol trial of LOw GI diet versus no dietary intervention to prevent recurrence of foetal macrosomia) study had reduced weight gain from early pregnancy and greater reported dietary health behaviours, e.g. food label reading, at 3 months postpartum but there was no significant difference in weight or BMI between the control and intervention groups at this time-point (Horan et al. 2014b).

The aim of this study was to determine which, if any, maternal characteristics and pregnancy dietary factors were associated with infant adiposity at 2 years of age in a cohort of the ROLO study (Walsh et al. 2012b) and to examine the effect of a low GI dietary intervention in pregnancy on maternal BMI 2 years postpartum.

\section{Methods}

Two hundred and eighty one mother and infant pairs from the ROLO study were included in this analysis. These mother and infant pairs were participants of the original ROLO study who agreed to return for follow-up at 2 years postpartum. The original ROLO study consisted of 800 secundigravida women who had previously given birth to a macrosomic baby ( $>4 \mathrm{~kg}$ ) and were, therefore, at high risk of delivering another macrosomic infant (Mahony et al. 2006). A power study performed when designing the ROLO study found that 360 women in each group (control and intervention) would be needed to detect a 0.25 standard deviation difference in the primary outcome; birth weight, with $90 \%$ power. Therefore, a sample size of 800 was considered sufficient to allow for drop-outs. The women were randomised to receive low GI dietary advice in early pregnancy or usual antenatal care, which did not include dietary advice. Detailed methodology and results of the ROLO study have previously been published (Walsh et al. 2010, 2012a). In brief, women were randomised using computer generated allocations in a ratio of $1: 1$ stored in sealed opaque envelopes. Once randomised, it was not possible to blind participants or researchers to study group affiliation. Women from the intervention group attended 1-2 hour dietitian-led low GI dietary advice sessions at week 14 of pregnancy in groups of 2-6 participants. Dietary education was designed to meet Irish nutritional recommendations for pregnant women (DOHC 2005). Women were not given specific information on their energy requirements or advice on gestational weight gain, however, they were advised not to 'eat for two' and to consume an additional 200-300 kcal per day in the last trimester of pregnancy. Women were educated on the definition of GI and the rationale for its use during pregnancy and written information was given about GI along with a list of foods with high and low GI values. Women were encouraged to choose low GI instead of high GI foods. A list of low GI recipes was also provided and women were emailed additional low GI recipes during their pregnancy. Demographic, well-being and lifestyle questionnaires were returned by 28 weeks gestation and 3-day food diaries were completed during each trimester of pregnancy. Maternal weight and height were recorded in early pregnancy and maternal weight was also measured throughout gestation. Offspring birthweight, length, circumferences and skinfold thicknesses were measured at birth. As mentioned, the primary outcome was birthweight, which was significantly lower in the intervention group. The secondary outcomes of reduced maternal gestational weight gain and insulin intolerance were also achieved.

\section{Inclusion and exclusion criteria}

Participants were secundigravida women who had previously given birth to a macrosomic infant $(>4 \mathrm{~kg})$. They were required to have sufficient literacy and English language fluency to understand the intervention and complete questionnaires. The women had healthy, singleton pregnancies with no intrauterine growth abnormalities. All participants were invited to return for a follow-up appointment with their infant 2 years postpartum and infants were eligible for inclusion until they reached 2 years 6 months old.

\section{Maternal demographics, lifestyle and infant feeding practices}

Of the 800 participants of the ROLO study, 281 returned at 2 years postpartum. Questions on lifestyle habits were taken from the SLAN (Survey of Lifestyle, Attitudes and Nutrition in Ireland) (Harrington et al. 2008) questionnaire including questions on physical activity, smoking, education and food label reading.

\section{Maternal and infant anthropometry}

Maternal weight, height and mid-upper arm circumference were measured at the first antenatal consultation and BMI calculated. Maternal weight was measured at each subsequent consultation and gestational weight gain calculated. Maternal 
weight and mid-upper arm circumference were also measured 2 years postpartum and BMI calculated.

Infant weight, length, mid-upper arm, abdominal, hip and thigh circumference, and biceps, triceps, subscapular and thigh skinfold thickness were measured at 2 years of age. World Health Organisation (WHO) growth standards were used to convert these measurements to z-scores which adjusts for infant age at exam and gender and report standard deviations away from the median (Horan et al. 2014a; WHO 2006). Waist:hip, waist:length and subscapular:triceps skinfold ratios as well as sum of triceps and subscapular skinfold thicknesses and sum of all skinfold thicknesses were calculated as markers of infant adiposity.

\section{Maternal dietary intakes during pregnancy}

Three-day food diaries were completed during each trimester of pregnancy and used to determine macronutrient intake as well as the GI and load of the women's diet. Macronutrients were expressed as a percentage of total energy. Dietary intake in each trimester of pregnancy was examined separately. Underreporting was estimated using Goldberg ratios, i.e. the ratio of energy intake to estimated basal metabolic rate (Goldberg et al. 1991). Basal metabolic rate was calculated using Schofield equations and a Goldberg ratio of $\leq 0.9$ was used to identify underreporters (Goldberg et al. 1991; McGowan and McAuliffe 2012; Schofield 1984). Full methodology for entry and analysis of the dietary intake of participants has previously been published (McGowan et al. 2013).

\section{Statistical analysis}

Statistical analysis was completed using SPSS (Statistical Package for the Social Sciences) software version 20.0. Control and intervention groups were combined for analysis but study group was controlled for in all final models. Correlations, independent sample t-tests, chi-squared tests and analysis of variance (ANOVA) was used as appropriate to identify maternal characteristics and macronutrient intakes associated with infant adiposity at 2 years of age $(p<0.05)$. Variables examined included macronutrient intake for each trimester, parental height, weight and BMI during pregnancy and maternal weight and BMI at 2 years months postpartum, gestational weight gain, reported maternal physical activity and smoking during pregnancy. Maternal physical activity, smoking and alcohol intake was also reported at 2 years postpartum. Data on maternal ethnicity, maternal age at delivery, marital/partner status and GI and load was also recorded during pregnancy. Variables found to be significantly associated with infant anthropometry at 2 years of age were further analysed using simple linear regression then input into final multiple regression models using a forced enter and backwards stepwise approach. This resulted in any non- significant variables being discarded from the model in a stepwise manner. Variables known to affect infant adiposity (birthweight, maternal education level as a marker of socioeconomic status, age in weeks at 2-year follow-up exam, infant gender and breastfeeding duration) were controlled for using forced enter multiple regression in these models. Models predictive of infant anthropometric measurements for which z-scores were available were not adjusted for infant age and gender as these factors are taken into account when converting to z-scores. Membership of the control or intervention group and maternal dietary underreporting (Goldberg ratio $\leq 0.9$ ) were also included by forced enter multiple regression in these models and analysis was carried out excluding underreporters. Multiple linear regression resulted in a best and final model and models that were statistically significant overall $(p<0.05)$ were chosen as those which best predicted neonatal anthropometric measurements. Maternal weight and BMI was compared between the control and intervention groups at 2 years postpartum using independent sample t-tests.

\section{Results}

\section{Maternal demographics, lifestyle and infant feeding practices}

Maternal demographic, anthropometric and lifestyle characteristics at baseline and 2-year follow-up are displayed in Table 1. Women who returned at 2 years postpartum were aged $32.96 \pm$ 3.92 years at delivery, $92.3 \%$ of them were of white Irish ethnicity while $6.8 \%$ were of white non-Irish and $0.3 \%$ were each of Chinese, Indian and Filipino/South East Asian ethnicity. Fifty-nine percent had completed third level education, while $22 \%$ had completed some third level education, $15.3 \%$ had completed second level education and $3.7 \%$ had completed some second level education. Ninety-seven point nine percent of women reported they were non-smokers in early pregnancy, while $2.1 \%$ reported smoking. At 2 years postpartum $86.5 \%$ reported they were non-smokers, while $13.5 \%$ reported smoking. Maternal BMI in early pregnancy was $26.22 \pm$ $4.54 \mathrm{~kg} / \mathrm{m}^{2}$, while at 2 years postpartum maternal BMI was $25.95 \pm 4.50 \mathrm{~kg} / \mathrm{m}^{2}$. There was no difference between the control and intervention group at either time-point in maternal BMI ( $p=0.524$ and $p=0.311$ respectively). While maternal gestational weight gain was lower in the intervention group in the original ROLO study, gestational weight gain in this cohort was $13.59 \pm 4.61$ and did not differ significantly between the control and intervention groups $(p=0.317)$.

With regard to infant feeding practices; $64.9 \%$ of women reported breastfeeding their second child while $35.1 \%$ did not breastfeed. The mean duration of breastfeeding was 13.04 \pm 23.23 weeks. The age infants were first given drinks other than breast milk (including formula milk) was 12.59 
Table 1 Baseline and 2-year follow-up maternal demographic and lifestyle characteristics

\begin{tabular}{llll}
\hline & Total mean & SD & $p$-value \\
\hline Mother age at delivery (years) & 32.96 & 3.92 & 0.325 \\
Baseline strenuous activity (No. of 20-min intervals/week) & 2.00 & 1.02 & 0.288 \\
Baseline moderate activity (No. of 20-min intervals/week) & 3.13 & 1.99 & 0.020 \\
Baseline mild activity (No. of 20-min intervals/week) & 4.01 & 2.37 & 0.218 \\
Mother height (cm) & 165.44 & 14.17 & 0.893 \\
Mother weight (kg) & 72.60 & 13.33 & 0.533 \\
Mother mid upper arm circumference at baseline (cm) & 29.27 & 3.31 & 0.297 \\
Gestational weight gain (kg) & 13.59 & 4.61 & 0.317 \\
Mother BMI baseline (kg/m ${ }^{2}$ ) & 26.22 & 4.54 & 0.524 \\
Mother weight at 2 years (kg) & 71.71 & 13.43 & 0.307 \\
Mother mid-upper arm circumference at 2 years (cm) & 29.11 & 3.60 & 0.769 \\
Mother BMI at 2 years (kg/m ${ }^{2}$ ) & 25.95 & 4.50 & 0.311 \\
Duration of breastfeeding (weeks) & 13.04 & 23.23 & 0.082 \\
Age given drinks other than breastmilk (weeks) & 12.59 & 16.66 & 0.937 \\
2-year strenuous activity (No. of 20-min intervals/week) & 0.91 & 1.46 & 0.106 \\
2-year moderate activity (No. of 20 min intervals/week) & 2.12 & 2.44 & 0.012 \\
2-year mild activity (No. of 20 min intervals/week) & 2.26 & 2.88 & 0.752 \\
\hline
\end{tabular}

Comparison of control and intervention groups carried out using independent sample t-tests $B M I$ body mass index \pm 16.66 weeks, while solids were reportedly first introduced at $19.56 \pm 5.08$ weeks. There was no significant difference between the control and intervention groups in infant feeding practices.

\section{Loss to follow-up}

A comparison of baseline characteristics of participants and those lost to follow-up is displayed in electronic supplementary material (ESM1). The only significant difference observed between the groups was a greater reported frequency of 20-min intervals of moderate physical activity per week in those lost to follow-up $(3.57 \pm 2.44$ vs $3.00 \pm 1.85$ intervals, $p=0.020$ ).

\section{Infant anthropometry}

Infant anthropometric characteristics are displayed in Table 2. Infant adiposity, estimated using ratios and sums of infant anthropometry measurements, did not differ between the control and intervention groups except for hip circumference which was lower in the control group in this cohort which only contained participants who had both completed food diaries during pregnancy and returned at 2-years postpartum $(49.02 \pm 3.55$ vs $49.96 \pm 3.22)$. Classification of infants according to WHO BMI-for-age cut-offs (WHO 2006) resulted in $4(1.4 \%)$ being classified as "wasted", $204(72.1 \%)$ as "normal", $51(18 \%)$ as "at risk of overweight", 22 (7.8\%) as "overweight" and $2(0.7 \%)$ as "obese".

\section{Associations between maternal body composition and lifestyle and offspring adiposity at 2 years of age}

Unadjusted associations between maternal body composition and offspring adiposity at 2 years of age are displayed in ESM2 while adjusted associations are displayed in Table 3. Maternal BMI at 2 years postpartum was positively associated with BMI-for-age $\mathrm{z}$-score $(B=0.105, p=0.015)$. Maternal height was negatively associated with 2-year-old sum of all skinfold thicknesses, a measure of overall adiposity, $(B=-0.371, p=0.003)$ and with 2-year-old thigh skinfold thickness $(B=-0.240, p=0.004)$. In terms of lifestyle; 2year-old waist:length ratio, a measure of central adiposity, was positively associated with maternal reported minutes sitting per weekday during early pregnancy $(B=4.71 \mathrm{e}-05$, $p=0.019$ ).

\section{Associations between maternal macronutrient intake and GI during pregnancy and offspring adiposity at 2 years of age}

Unadjusted associations between maternal dietary intake and offspring adiposity at 2 years of age are displayed in ESM2, while adjusted associations are displayed in Table 3. Maternal dietary intake during pregnancy is described in ESM3. A small number of maternal dietary factors were associated with several measures of offspring weight and adiposity at 2 years of age. Maternal trimester 2 polyunsaturated fat intake was negatively associated with 2-year-old waist:length ratio 
Table 2 Anthropometric characteristics of offspring at birth and at 2 years of age

\begin{tabular}{|c|c|c|c|c|}
\hline & $\begin{array}{l}n \\
\text { (intervention) }\end{array}$ & $\begin{array}{l}n \\
\text { (total) }\end{array}$ & Mean & SD \\
\hline Birth length $(\mathrm{cm})$ & 116 & 234 & 52.94 & 2.21 \\
\hline Birth head circumference $(\mathrm{cm})$ & 67 & 132 & 35.83 & 1.20 \\
\hline Birth abdominal circumference $(\mathrm{cm})$ & 69 & 137 & 33.56 & 1.92 \\
\hline Birth thigh circumference $(\mathrm{cm})$ & 69 & 137 & 16.21 & 1.70 \\
\hline Birth chest circumference $(\mathrm{cm})$ & 69 & 137 & 35.58 & 2.28 \\
\hline Birth hip circumference $(\mathrm{cm})$ & 68 & 136 & 33.76 & 2.32 \\
\hline Birth mid-upper arm straight $(\mathrm{cm})$ & 69 & 137 & 12.53 & 1.15 \\
\hline Birth subscapular skinfold thickness (mm) & 54 & 114 & 6.90 & 1.53 \\
\hline Birth triceps skinfold thickness (mm) & 54 & 114 & 6.99 & 1.56 \\
\hline Birth biceps skinfold thickness (mm) & 54 & 114 & 6.73 & 1.49 \\
\hline Birth thigh skinfold thickness (mm) & 54 & 114 & 7.88 & 1.73 \\
\hline Birth weight $(\mathrm{kg})$ & 133 & 280 & 4.06 & 4.59 \\
\hline Birth sum of skinfold thicknesses (mm) & 54 & 114 & 28.50 & 5.23 \\
\hline Birth waist:hip ratio & 68 & 136 & 1.00 & 0.06 \\
\hline Birth sum of triceps and subscapular skinfold thickness (mm) & 54 & 114 & 13.89 & 2.76 \\
\hline Birth subscapular:triceps skinfold thickness ratio & 54 & 114 & 1.01 & 0.20 \\
\hline Birth waist circumference:length ratio & 60 & 118 & 0.63 & 0.04 \\
\hline 2 year length-for-age $z$-score & 134 & 281 & 0.98 & 5.95 \\
\hline 2-year head circumference-for-age z-score & 130 & 276 & 1.37 & 1.37 \\
\hline 2-year abdominal circumference $(\mathrm{cm})$ & 132 & 278 & 50.40 & 4.22 \\
\hline 2-year thigh circumference $(\mathrm{cm})$ & 132 & 279 & 27.43 & 2.69 \\
\hline 2-year chest circumference $(\mathrm{cm})$ & 127 & 271 & 50.59 & 2.91 \\
\hline 2-year hip circumference $(\mathrm{cm})$ & 113 & 234 & 49.47 & 3.42 \\
\hline 2-year mid-upper arm circumference-for-age z-score & 132 & 279 & 1.13 & 1.12 \\
\hline 2-year subscapular skinfold thickness-for-age z-score & 112 & 219 & 0.73 & 1.12 \\
\hline 2-year triceps skinfold thickness-for-age z-score & 109 & 218 & 1.15 & 1.15 \\
\hline 2-year biceps skinfold thickness (mm) & 112 & 223 & 7.80 & 2.23 \\
\hline 2-year thigh skinfold thickness (mm) & 112 & 220 & 15.67 & 5.76 \\
\hline 2-year weight-for-age z-score & 134 & 281 & 0.69 & 1.01 \\
\hline 2-year weight-for-length z-score & 134 & 280 & 0.79 & 5.59 \\
\hline 2-year BMI-for-age z-score & 134 & 281 & 0.42 & 1.10 \\
\hline 2-year waist circumference:length ratio & 132 & 278 & 0.56 & 0.05 \\
\hline 2-year waist:hip circumference ratio & 113 & 234 & 1.02 & 0.08 \\
\hline 2-year sum of skinfold thicknesses (mm) & 112 & 216 & 40.82 & 8.14 \\
\hline 2-year sum of triceps and subscapular skinfold thicknesses (mm) & 112 & 218 & 17.46 & 3.40 \\
\hline 2-year subscapular:triceps skinfold thickness ratio & 112 & 218 & 0.74 & 0.21 \\
\hline
\end{tabular}

$B M I$ body mass index
$(B=-0.005, p=0.017)$. Trimester $1 \mathrm{GI}$ was negatively associated with 2-year old BMI-for-age z-score $(B=-0.045$, $p=0.014)$, hip circumference $(B=-0.180, p=0.026)$ and sum of all skinfold thicknesses $(B=-0.405, p=0.023)$.

\section{Discussion}

The main findings of this follow-up study were that, whilst maternal BMI at 2 years postpartum was positively associated with 2 - year-old BMI-for-age z-score, maternal height was negatively associated with 2-year-old sum of all skinfold thicknesses, a measure of overall adiposity. In terms of associations between maternal dietary factors and offspring adiposity at 2 years of age; trimester 3 saturated fat intake was positively associated with 2year-old weight-for-age z-score. Conversely, maternal trimester 2 polyunsaturated fat intake was negatively associated with 2 year-old waist:length ratio, a measure of central adiposity. Maternal trimester 1 GI was negatively associated with 2-yearold BMI-for-age z-score, and sum of all skinfold thicknesses. 
Table 3 Association of maternal and characteristics and maternal diet with offspring adiposity at 2 years of age- Multiple linear regression excluding underreporters*

\begin{tabular}{|c|c|c|c|c|c|c|}
\hline & $B$ & SEB & $p$ & $R^{2}$ adj & $F$ & $P$ \\
\hline \multicolumn{7}{|l|}{ Weight-for-age z-score } \\
\hline Mother MUA circumference baseline $(\mathrm{cm})$ & 0.065 & 0.035 & 0.065 & & & \\
\hline Trimester 3 saturated fat (\%TE) & 0.048 & 0.024 & 0.046 & 0.205 & 5.316 & $<0.001$ \\
\hline 2-year mother weight $(\mathrm{kg})$ & 0.030 & 0.014 & 0.035 & & & \\
\hline 2-year mother BMI $\left(\mathrm{kg} / \mathrm{m}^{2}\right)$ & -0.111 & 0.042 & 0.009 & & & \\
\hline $\begin{array}{l}\text { Age given drinks other than breast milk } \\
\text { (weeks) }\end{array}$ & -0.010 & 0.005 & 0.057 & & & \\
\hline \multicolumn{7}{|l|}{ BMI-for-age z-score } \\
\hline Trimester $1 \mathrm{GI}$ & -0.045 & 0.018 & 0.014 & & & \\
\hline 2-year mother weight $(\mathrm{kg})$ & -0.025 & 0.015 & 0.087 & 0.081 & 3.340 & 0.002 \\
\hline 2-year mother BMI $\left(\mathrm{kg} / \mathrm{m}^{2}\right)$ & 0.105 & 0.043 & 0.015 & & & \\
\hline \multicolumn{7}{|l|}{ MUA circumference-for-age z-score } \\
\hline Mother baseline smoker (yes/no) & 2.603 & 0.881 & 0.004 & 0.078 & 3.277 & 0.008 \\
\hline \multicolumn{7}{|l|}{ Waist:length ratio } \\
\hline $\begin{array}{l}\text { Baseline maternal minutes sitting per } \\
\text { weekday }\end{array}$ & $4.71 \mathrm{E}-05$ & 0.000 & 0.019 & & & \\
\hline Mother height $(\mathrm{cm})$ & 0.000 & 0.000 & 0.054 & 0.142 & 3.807 & $<0.001$ \\
\hline Trimester 2 Polyunsaturated fat (\%TE) & -0.005 & 0.002 & 0.017 & & & \\
\hline Trimester 3 Polyunsaturated fat (\%TE) & -0.004 & 0.002 & 0.070 & & & \\
\hline \multicolumn{7}{|l|}{ Sum of all skinfold thicknesses } \\
\hline Mother height $(\mathrm{cm})$ & -0.371 & 0.122 & 0.003 & 0.070 & 2.365 & 0.020 \\
\hline Trimester $1 \mathrm{GI}$ & -0.405 & 0.176 & 0.023 & & & \\
\hline \multicolumn{7}{|l|}{ Subscapular:triceps skinfold thickness ratio } \\
\hline Trimester $1 \mathrm{GI}$ & 0.009 & 0.004 & 0.029 & 0.088 & 2.782 & 0.007 \\
\hline Trimester 2 Saturated Fat (\%TE) & 0.018 & 0.005 & 0.001 & & & \\
\hline
\end{tabular}

Multiple linear regression analysis carried out. Adjusted for maternal education level, infant age in weeks at 2-year follow-up exam, infant gender, breastfeeding duration and study group. Maternal dietary underreporters removed $(*$ Goldberg ratio $\leq 0.9$ ). Maternal dietary intake derived from food diaries in each trimester of pregnancy

$T E$ total energy, GI glycaemic index, BMI body mass index, $M U A$ mid upper arm
Our finding that infant BMI-for-age z-score at 2 years of age was positively associated with maternal BMI at 2 years postpartum was independent of maternal BMI in early pregnancy and of gestational weight gain, neither of which were significantly associated. This positive association between maternal and offspring adiposity has been observed in several studies (Gibson et al. 2007; Magarey et al. 2003; McDonald et al. 2009; Strauss and Knight 1999). Evidence shows that maternal, and indeed paternal, eating habits, lifestyle and nutritional knowledge influence that of family members in a variety of ways including behaviour modelling (Matheson et al. 2006; Turer et al. 2013), infant feeding practices (Clark et al. 2007; Li et al. 2003; Perrine et al. 2012) and gatekeeping of food-provision into the house, cooking methods and portion sizes served (Nguyen et al. 1996; Waxman and Stunkard 1980; Wild et al. 1994). Obese mothers are thought to exert less control over their children's eating habits and structure at mealtimes than normal weight mothers (Baughcum et al. 2001; Wardle et al. 2002). Genetic factors are also likely to account in part for some of the positive associations between maternal and child overweight and obesity observed in the literature (Bouchard 2009). However, maternal overweight and obesity in the years post-partum has also been found to contribute to the positive correlation between maternal and offspring overweight (Jääskeläinen et al. 2011).

Maternal height was negatively associated with 2-year-old sum of all skinfold thicknesses, a measure of overall adiposity. Parental height is well known to affect offspring height with midparental height used to predict final offspring height (Aulchenko et al. 2009; Tanner et al. 1970). Parental height is correlated with socioeconomic status (Cardoso and Caninas 2010; Cavelaars et al. 2000; Subramanian et al. 2011) and higher rates of overweight and obesity in lower socioeconomic groups have been attributed in part to the lower energy requirements of individuals with shorter stature (Cecil etal. 2005; Heineck 2006; Lobstein and Frelut 2003). However, socioeconomic status is becoming less intrinsically linked to height as living conditions, food security and average height improve across the social strata and rather, parental height alone may now be the main predictor acting only as an artefact of ancestral socioeconomic status (Galobardes et al. 2012). Infant length-for-age $z$-score was not associated with maternal height in this cohort. This effect may be mediated by 
maternal higher socioeconomic status being associated with improved dietary and lifestyle habits postpartum (Gibbs and Forste 2014; Hupkens et al. 1998; Sallis et al. 1996; Shrewsbury and Wardle 2008; Vereecken et al. 2004; Wang 2001); however, these factors were not comprehensively examined by this study.

Maternal trimester 1 GI was negatively associated with 2year-old BMI-for-age z-score and sum of all skinfolds. Several studies have found that maternal GI in pregnancy is positively associated with macrosomia (Clapp 1997; Moses et al. 2006; Scholl et al. 2004) and offspring adiposity (Donnelly et al. 2014; Okubo et al. 2014), while others have found no effect (Moses et al. 2007; Walsh et al. 2012a). A recent study by Okubo et al. (2014) found that maternal GI in early pregnancy was positively associated with offspring fat mass at 4 and at 6 years of age but not at birth. Observational studies focusing on sugars and carbohydrate intakes rather than GI have also found associations with offspring adiposity; Murrin et al. (2013) found that maternal sugar intake in early pregnancy was positively associated with offspring adiposity at 5 years of age while studies by Pereirade-Silva et al. ( 2014) and Moore et al. (2004) found that maternal carbohydrate intake during pregnancy was positively associated with neonatal adiposity. Therefore, the negative relationship observed in this cohort was counterintuitive. However, when further analysis was carried out and the control and intervention groups were examined separately it was found that this negative association was only present in the control group. Therefore, it might be speculated that this relationship may have been attenuated by the low GI intervention in later pregnancy. Of course, the nature of this retrospective analysis precludes determination of causality and further studies would be required to explore any association further.

Maternal trimester 3 saturated-fat intake was positively associated with 2-year-old weight-for-age z-score. A study by Murrin et al. ( 2013) found that maternal trimester 1 saturated fat intake was positively associated with offspring overweight and obesity at 5 years of age while a study by Ladino et al. (2014) also found that maternal total fat intake was positively associated with offspring adiposity up to 18 months. Previously, we also observed a similar positive association at birth between neonate central adiposity and maternal trimester 3 saturated-fat intake (Horan et al. 2014c), while, at 6 months of age, central adiposity was found to be positively associated with trimester 2 saturated-fat intake (Horan et al. 2016).

Finally, there was no significant difference observed in maternal BMI between the control and intervention groups at 2 years postpartum. There is little data available on the effect of low GI or healthy eating diet in pregnancy on maternal weight postpartum with the exception of women with GDM. Pregnancy interventions in GDM have been found to have little impact on maternal dietary habits or weight postpartum despite knowledge of the mothers that GDM results in greater risk of later type II diabetes (Evans et al. 2010; Fehler et al.
2007; Louie et al. 2015; Stage et al. 2004). However, it should be noted that, unlike in the original ROLO study, there was no significant reduction in gestational weight gain in the intervention group of this cohort, who returned for follow-up at 2 years postpartum and had completed food diaries during pregnancy despite significant reduction in GI observed postintervention.

This study had some limitations; an infant food frequency questionnaire would have allowed us to control for the dietary intake of the 2 year olds. However, we did have information on infant feeding and weaning practices and controlled for duration of breastfeeding in all final models. Another limitation was that data from this cohort may not be generalizable to other populations as this was a relatively well-educated group with a high incidence of macrosomia and concomitant risk of offspring obesity. This study had a high rate of loss to followup due to a delay in commencing 2-year old follow-up data collection as the study was not originally designed to be continued beyond 6 months postpartum. This, unfortunately, resulted in this study being inadequately powered to examine the effect of the intervention on offspring adiposity. However, loss to follow-up was largely logistic rather than to do with reluctance to return, and this study still involved a large cohort particularly suitable for examination of the association of maternal diet and lifestyle during pregnancy and offspring adiposity.

\section{Conclusion}

Maternal BMI 2 years postpartum was positively associated with offspring adiposity at 2 years of age while maternal height was negatively associated. The quality of maternal dietary fat was a factor as saturated fat intake during pregnancy was positively associated with offspring adiposity. Finally, a low GI pregnancy intervention had no effect on maternal BMI 2 years postpartum. While further research is necessary, both pregnancy and the postpartum period may be early opportunities to combat childhood overweight and obesity.

Acknowledgements The authors would like to thank Jacinta Byrne, research midwife, who carried out data collection and Ricardo Segurado who gave statistical advice.

\section{Compliance with ethical standards}

Funding This study was supported by the Health Research Board Ireland, the Health Research Centre for Health and Diet Research, The National Maternity Hospital Medical Fund and the European Union's Seventh Framework Programme (FP7/2007-2013), project EarlyNutrition under grant agreement No. 289346.

Conflict of interest The authors declare that they have no conflict of interest. 
Ethical approval All procedures performed in studies involving human participants were in accordance with the ethical standards of the institutional research committee and with the 1964 Helsinki declaration and its later amendments.

Open Access This article is distributed under the terms of the Creative Commons Attribution 4.0 International License (http:// creativecommons.org/licenses/by/4.0/), which permits unrestricted use, distribution, and reproduction in any medium, provided you give appropriate credit to the original author(s) and the source, provide a link to the Creative Commons license, and indicate if changes were made.

\section{References}

Alexandra P, Vassilios B, Alexandra V, George K, Vassiliki L, Chryssa B (2011) Population-based trends of pregnancy outcome in obese mothers: what has changed over 15 years. Obesity 19:1861-1865

Aulchenko YS, Struchalin MV, Belonogova NM, Axenovich TI, Weedon MN, Hofman A, Uitterlinden AG, Kayser M, Oostra BA, van Duijn CM (2009) Predicting human height by Victorian and genomic methods. Eur J Hum Genet 17:1070-1075

Barker D (2004) The developmental origins of adult disease. J Am Coll Nutr 23:588S-595S

Baughcum AE, Powers SW, Johnson SB, Chamberlin LA, Deeks CM, Jain A, Whitaker RC (2001) Maternal feeding practices and beliefs and their relationships to overweight in early childhood. J Dev Behav Pediatr 22:391-408

Black RE, Victora CG, Walker SP, Bhutta ZA, Christian P, De Onis M, Ezzati M, Grantham-McGregor S, Katz J, Martorell R (2013) Maternal and child undernutrition and overweight in low-income and middle-income countries. Lancet 382:427-451

Blair NJ, Thompson JM, Black PN, Becroft DM, Clark PM, Han DY, Robinson E, Waldie KE, Wild CJ, Mitchell EA (2007) Risk factors for obesity in 7-year-old European children: the Auckland Birthweight Collaborative Study. Arch Dis Child 92:866-871

Bouchard C (2009) Childhood obesity: are genetic differences involved? Am J Clin Nutr 89:1494S-1501S

Brion M-JA, Ness AR, Rogers I, Emmett P, Cribb V, Smith GD, Lawlor DA (2010) Maternal macronutrient and energy intakes in pregnancy and offspring intake at $10 \mathrm{y}$ : exploring parental comparisons and prenatal effects. Am J Clin Nutr 91:748-756

Cardoso HF, Caninas M (2010) Secular trends in social class differences of height, weight and BMI of boys from two schools in Lisbon, Portugal (1910-2000). Econ Human Biol 8:111-120

Catalano P, Ehrenberg H (2006) Review article: The short-and long-term implications of maternal obesity on the mother and her offspring. BJOG 113:1126-1133

Cavelaars A, Kunst AE, Geurts J, Crialesi R, Grötvedt L, Helmert U, Lahelma E, Lundberg O, Mielck A, Rasmussen NK (2000) Persistent variations in average height between countries and between socio-economic groups: an overview of 10 European countries. Ann Hum Biol 27:407-421

Cecil J, Watt P, Murrie I, Wrieden W, Wallis D, Hetherington M, BoltonSmith C, Palmer C (2005) Childhood obesity and socioeconomic status: a novel role for height growth limitation. Int J Obes 29:11991203

Clapp J (1997) Diet, exercise, and feto-placental growth. Arch Gynecol Obstet 260:101-108
Clark H, Goyder E, Bissell P, Blank L, Peters J (2007) How do parents' child-feeding behaviours influence child weight? Implications for childhood obesity policy. J Public Health 29:132-141

Cohen JF, Rifas-Shiman SL, Rimm EB, Oken E, Gillman MW (2011) Maternal trans fatty acid intake and fetal growth. Am J Clin Nutr. doi:10.3945/ajen.111.014530

Cuco G, Arija V, Iranzo R, Vila J, Prieto M, Fernández-Ballart J (2006) Association of maternal protein intake before conception and throughout pregnancy with birth weight. Acta Obstet Gynecol Scand 85:413-421

Curhan GC, Chertow GM, Willett WC, Spiegelman D, Colditz GA, Manson JE, Speizer FE, Stampfer MJ (1996a) Birth weight and adult hypertension and obesity in women. Circulation 94:1310 1315

Curhan GC, Willett WC, Rimm EB, Spiegelman D, Ascherio AL, Stampfer MJ (1996b) Birth weight and adult hypertension, diabetes mellitus, and obesity in US men. Circulation 94:3246-3250

De Vries PS, Gielen M, Rizopoulos D, Rump P, Godschalk R, Hornstra G, Zeegers MP (2014) Association between polyunsaturated fatty acid concentrations in maternal plasma phospholipids during pregnancy and offspring adiposity at age 7: The MEFAB cohort. Prostaglandins Leukotrienes and Essential Fatty Acids 91(3):81-85

Dirix CE, Kester AD, Hornstra G (2009) Associations between term birth dimensions and prenatal exposure to essential and trans fatty acids. Early Hum Dev 85:525-530

DOHC (2005) Healthy eating for pregnancy. DOHC, Dublin

Donahue SM, Rifas-Shiman SL, Gold DR, Jouni ZE, Gillman MW, Oken E (2011) Prenatal fatty acid status and child adiposity at age 3 y: results from a US pregnancy cohort. Am J Clin Nutr 93:780-788

Donnelly JM, Walsh JM, Byrne J, Molloy EJ, McAuliffe FM (2014) Impact of maternal diet on neonatal anthropometry: a randomized controlled trial. Pediatr Obes. doi:10.1111/j.2047-6310.2013.00216.x

Evans MK, Patrick LJ, Wellington CM (2010) Health behaviours of postpartum women with a history of gestational diabetes. Can J Diabetes 34:227-232

Fehler KL, Kennedy LE, McCargar LJ, Bell RC, Ryan EA (2007) Postpartum dietary changes in women with previous gestational diabetes mellitus. Can J Diabetes 31:54-61

Fisher S, Kim S, Sharma A, Rochat R, Morrow B (2013) Is obesity still increasing among pregnant women? Prepregnancy obesity trends in 20 states, 2003-2009. Prev Med 56:372-378

Galobardes B, McCormack VA, McCarron P, Howe LD, Lynch J, Lawlor DA, Smith GD (2012) Social inequalities in height: persisting differences today depend upon height of the parents. PLoS ONE 7: e29118

Gibbs B, Forste R (2014) Socioeconomic status, infant feeding practices and early childhood obesity. Paediatr Obes 9:135-146

Gibson LY, Byrne SM, Davis EA, Blair E, Jacoby P, Zubrick SR (2007) The role of family and maternal factors in childhood obesity. Med J Aust 186:591

Goldberg G, Black A, Jebb S, Cole T, Murgatroyd P, Coward W, Prentice A (1991) Critical evaluation of energy intake data using fundamental principles of energy physiology: 1 . derivation of cut-off limits to identify under-recording. Eur J Clin Nutr 45:569-581

Harrington J, Perry I, Lutomski J, Morgan K, McGee H, Shelley E, Watson D, Barry M (2008) SLÁN 2007: survey of lifestyle, attitudes and nutrition in Ireland - dietary habits of the Irish population. Department of Health and Children, Dublin

Hauner H, Much D, Vollhardt C, Brunner S, Schmid D, Sedlmeier E-M, Heimberg E, Schuster T, Zimmermann A, Schneider K-TM (2012) Effect of reducing the n-6:n-3 long-chain PUFA ratio during pregnancy and lactation on infant adipose tissue growth within the first year of life: an open-label randomized controlled trial. Am J Clin Nutr 95:383-394

Heineck G (2006) Height and weight in Germany, evidence from the German Socio-Economic Panel, 2002. Econ Hum Biol 4:359-382 
Horan M, Gibney E, Molloy E, McAuliffe F (2014a) Methodologies to assess paediatric adiposity. Ir J Med Sci 184(1):53-68. doi:10.1007/ s11845-014-1124-1

Horan MK, McGowan CA, Gibney ER, Donnelly JM, McAuliffe FM (2014b) Maternal diet and weight at 3 months postpartum following a pregnancy intervention with a low glycaemic index diet: results from the ROLO Randomised Control Trial. Nutrients 6(7):29462955. doi:10.3390/nu6072946

Horan MK, McGowan CA, Gibney ER, Donnelly JM, McAuliffe FM (2014c) Maternal low glycaemic index diet, fat intake and postprandial glucose influences neonatal adiposity-secondary analysis from the ROLO study. Nutr J 13:78

Horan MK, McGowan CA, Gibney ER, Byrne J, Donnelly JM, McAuliffe FM (2016) Maternal nutrition and glycaemic index during pregnancy impacts on offspring adiposity at 6 months of age: analysis from the ROLO Randomised Controlled Trial. Nutr 8:7

Hupkens CL, Knibbe RA, Van Otterloo AH, Drop MJ (1998) Class differences in the food rules mothers impose on their children: a cross-national study. Soc Sci Med (1982) 47:1331-1339

Jääskeläinen A, Pussinen J, Nuutinen O, Schwab U, Pirkola J, Kolehmainen M, Järvelin M, Laitinen J (2011) Intergenerational transmission of overweight among Finnish adolescents and their parents: a 16-year follow-up study. Int J Obes 35:1289-1294

Ladino L, Morreno-Torres R, Campos D, Baltazar M-C, Campoy C (2014) The maternal ingestion of sugar, fat and sodium during pregnancy is associated with the adiposity of children up to 18 months. Power of Programming Conference abstract book. http:// munich2014.project-earlynutrition.eu/:27. Accessed May 2016

Lau C, Rogers JM, Desai M, Ross MG (2011) Fetal programming of adult disease: implications for prenatal care. Obstet Gynecol 117:978-985

Li R, Jewell S, Grummer-Strawn L (2003) Maternal obesity and breastfeeding practices. Am J Clin Nutr 77:931-936

Lobstein T, Frelut ML (2003) Prevalence of overweight among children in Europe. Obes Rev 4:195-200

Louie JCY, Markovic TP, Ross GP, Foote D, Brand-Miller JC (2015) Effect of a low glycaemic index diet in gestational diabetes mellitus on post-natal outcomes after 3 months of birth: a pilot follow-up study. Matern Child Nutr 11(3):409-414

Magarey AM, Daniels LA, Boulton TJ, Cockington RA (2003) Predicting obesity in early adulthood from childhood and parental obesity. Int J Obes 27:505-513

Mahony R, Walsh C, Foley ME, Daly L, O'Herlihy C (2006) Outcome of second delivery after prior macrosomic infant in women with normal glucose tolerance. Obstet Gynecol 107:857-862. doi:10.1097/ 01.AOG.0000203340.09961.0b

Maslova E, Rytter D, Bech BH, Henriksen TB, Rasmussen MA, Olsen SF, Halldorsson TI (2014a) Maternal protein intake during pregnancy and offspring overweight 20 y later. Am J Clin Nutr. doi:10.3945/ ajcn.113.082222

Maslova E, Rytter D, Bech BH, Henriksen TB, Rasmussen MA, Olsen SF, Halldorsson TI (2014b) Maternal protein intake during pregnancy and offspring overweight 20 y later. Am J Clin Nutr 100:1139-1148

Matheson DM, Robinson TN, Varady A, Killen JD (2006) Do MexicanAmerican mothers' food-related parenting practices influence their children's weight and dietary intake? J Am Diet Assoc 106:18611865. doi:10.1016/j.jada.2006.08.004

McDonald CM, Baylin A, Arsenault JE, Mora-Plazas M, Villamor E (2009) Overweight is more prevalent than stunting and is associated with socioeconomic status, maternal obesity, and a snacking dietary pattern in school children from Bogota. Colomb J Nutr 139:370 376

McGowan C, McAuliffe F (2012) Maternal nutrient intakes and levels of energy underreporting during early pregnancy. Eur J Clin Nutr 66: 906-913

McGowan CA, Walsh JM, Byrne J, Curran S, McAuliffe FM (2013) The influence of a low glycemic index dietary intervention on maternal dietary intake, glycemic index and gestational weight gain during pregnancy: a randomized controlled trial. Nutr J 12:140

Moon R, Harvey N, Robinson S, Ntani G, Davies J, Inskip H, Godfrey K, Dennison E, Calder P, Cooper C (2012) Maternal plasma polyunsaturated fatty acid status in late pregnancy is associated with offspring body composition in childhood. J Clin Endocrinol Metab 98: 299-307

Moore VM, Davies MJ, Willson KJ, Worsley A, Robinson JS (2004) Dietary composition of pregnant women is related to size of the baby at birth. J Nutr 134:1820-1826

Moses RG, Casey SA, Quinn EG, Cleary JM, Tapsell LC, Milosavljevic M, Petocz P, Brand-Miller JC (2014) Pregnancy and Glycemic Index Outcomes study: effects of low glycemic index compared with conventional dietary advice on selected pregnancy outcomes. Am J Clin Nutr 99:517-523

Moses RG, Luebcke M, Davis WS, Coleman KJ, Tapsell LC, Petocz P, Brand-Miller JC (2006) Effect of a low-glycemicindex diet during pregnancy on obstetric outcomes. Am J Clin Nutr 84:807-812

Moses RG, Luebke M, Petocz P, Brand-Miller JC (2007) Maternal diet and infant size $2 \mathrm{y}$ after the completion of a study of a low-glycemicindex diet in pregnancy. Am J Clin Nutr 86:1806-1806

Murrin C, Shrivastava A, Kelleher CC (2013) Maternal macronutrient intake during pregnancy and 5 years postpartum and associations with child weight status aged five. Eur J Clin Nutr 67:670-679. doi: 10.1038/ejen.2013.76

Nguyen VT, Larson DE, Johnson RK, Goran MI (1996) Fat intake and adiposity in children of lean and obese parents. Am J Clin Nutr 63: 507-513

Oken E, Gillman MW (2003) Fetal origins of obesity. Obes Res 11:496506

Okubo H, Crozier SR, Harvey NC, Godfrey KM, Inskip HM, Cooper C, Robinson SM (2014) Maternal dietary glycemic index and glycemic load in early pregnancy are associated with offspring adiposity in childhood: the Southampton Women's Survey. Am J Clin Nutr 100: 676-683

Parsons TJ, Power C, Manor O (2001) Fetal and early life growth and body mass index from birth to early adulthood in 1958 British cohort: longitudinal study. Br Med J 323:1331-1335

Pereira-da-Silva L, Cabo C, Moreira AC, Virella D, Guerra T, Camoes T, Silva AR, Neves R, Ferreira GC (2014) The adjusted effect of maternal body mass index, energy and macronutrient intakes during pregnancy, and gestational weight gain on body composition of full-term neonates. Am J Perinatol 31:875-882. doi:10.1055/s0033-1363502

Perrine CG, Scanlon KS, Li R, Odom E, Grummer-Strawn LM (2012) Baby-friendly hospital practices and meeting exclusive breastfeeding intention. Pediatrics 130:54-60

Reynolds R, Osmond C, Phillips D, Godfrey K (2010) Maternal BMI, parity, and pregnancy weight gain: influences on offspring adiposity in young adulthood. J Clin Endocrinol Metab 95:5365-5369

Rogers I (2003) The influence of birthweight and intrauterine environment on adiposity and fat distribution in later life. Int J Obes 27:755777

Sallis JF, Zakarian JM, Hovell MF, Hofstetter CR (1996) Ethnic, socioeconomic, and sex differences in physical activity among adolescents. J Clin Epidemiol 49:125-134

Sayer AA, Syddall HE, Dennison EM, Gilbody HJ, Duggleby SL, Cooper C, Barker DJ, Phillips DI (2004) Birth weight, weight at 1 $\mathrm{y}$ of age, and body composition in older men: findings from the Hertfordshire Cohort Study. Am J Clin Nutr 80:199-203

Schofield W (1984) Predicting basal metabolic rate, new standards and review of previous work Human nutrition. Clin Nutr 39:5-41

Scholl TO, Chen X, San Khoo C, Lenders C (2004) The dietary glycemic index during pregnancy: influence on infant birth weight, fetal 
growth, and biomarkers of carbohydrate metabolism. Am J Epidemiol 159:467-474

Serdula MK, Ivery D, Coates RJ, Freedman DS, Williamson DF, Byers T (1993) Do obese children become obese adults? A review of the literature. Prev Med 22:167-177. doi:10.1006/pmed.1993.1014

Shrewsbury V, Wardle J (2008) Socioeconomic status and adiposity in childhood: a systematic review of cross-sectional studies 1990 2005. Obesity 16:275-284

Srinivasan SR, Bao W, Wattigney WA, Berenson GS (1996) Adolescent overweight is associated with adult overweight and related multiple cardiovascular risk factors: the Bogalusa Heart Study. Metabolism 45:235-240

Stage E, Ronneby H, Damm P (2004) Lifestyle change after gestational diabetes. Diabetes Res Clin Pract 63:67-72

Strauss RS, Knight J (1999) Influence of the home environment on the development of obesity in children. Pediatrics 103:e85-e85

Subramanian S, Özaltin E, Finlay JE (2011) Height of nations: a socioeconomic analysis of cohort differences and patterns among women in 54 low-to middle-income countries. PLoS ONE 6:e18962

Tanner J, Goldstein H, Whitehouse R (1970) Standards for children's height at ages 2-9 years allowing for height of parents. Arch Dis Child 45:755-762

Turer CB, Stroo M, Brouwer RJ, Krause KM, Lovelady CA, Bastian LA, Peterson B, Østbye T (2013) Do high-risk preschoolers or overweight mothers meet AAP-recommended behavioral goals for reducing obesity? Acad Pediatr 13:243-250

Vereecken CA, Keukelier E, Maes L (2004) Influence of mother's educational level on food parenting practices and food habits of young children. Appetite 43:93-103. doi:10.1016/j.appet.2004.04.002
Walsh J, Mahony R, Foley M, Mc Auliffe F (2010) A randomised control trial of low glycaemic index carbohydrate diet versus no dietary intervention in the prevention of recurrence of macrosomia. BMC Pregnancy Childbirth 10:16

Walsh JM, McGowan CA, Mahony R, Foley ME, McAuliffe FM (2012a) Low glycaemic index diet in pregnancy to prevent macrosomia (ROLO study): randomised control trial. BMJ $\mathrm{Br}$ Med J 345

Walsh JM, McGowan CA, Mahony R, Foley ME, McAuliffe FM (2012a) Low glycaemic index diet in pregnancy to prevent macrosomia (ROLO study): randomised control trial. Br Med J 345:e5605. doi: 10.1136/bmj.e5605

Wang Y (2001) Cross-national comparison of childhood obesity: the epidemic and the relationship between obesity and socioeconomic status. Int J Epidemiol 30:1129-1136

Wardle J, Sanderson S, Guthrie CA, Rapoport L, Plomin R (2002) Parental feeding style and the inter-generational transmission of obesity risk. Obes Res 10:453-462

Waxman M, Stunkard AJ (1980) Caloric intake and expenditure of obese boys. J Pediatr 96:187-193

WHO WHOMGRSG (2006) WHO Child Growth Standards based on length/height, weight and age. Acta Paediatr 450:76, (Oslo, Norway: 1992) Supplement

Wild RA, Taylor EL, Knehans A, Cleaver V (1994) Matriarchal model for cardiovascular prevention. Obstet Gynecol Surv 49:147-152

Wu G, Bazer FW, Cudd TA, Meininger CJ, Spencer TE (2004) Maternal nutrition and fetal development. J Nutr 134:2169-2172

Yu Z, Sun J, Haas J, Gu Y, Li Z, Lin X (2007) Macrosomia is associated with high weight-for-height in children aged $1-3$ years in Shanghai, China. Int J Obes 32:55-60 